\title{
Risk of hypothermia in elderly patients with diabetes
}

\author{
H A W NEIL, J A DAWSON, J E BAKER
}

\begin{abstract}
The incidence of admissions of patients with hypothermia was determined to examine whether hypothermia was more common in elderly patients with diabetes than in the general population after diabetic metabolic emergency cases had been excluded. A prospective survey of three accident and emergency departments identified 134 cases of hypothermia admitted from a catchment population of almost 157000 aged 65 or over during the winters of 1981-2 to 1983-4. The predicted number of patients with diabetes in the population was nearly $5600(3.5 \%)$. Twenty three admissions for hypothermia (17\%) occurred in 20 patients with previously diagnosed diabetes. Women made up $87 \%$ of the diabetic admissions; the ratio of diabetic to non-diabetic admission rates in women was $7.9(95 \%$ confidence interval $5 \cdot 3$ to $12 \cdot 0)$. After excluding diabetic metabolic emergency admissions the ratio was $6 \cdot 4$. The ratio in men was $2 \cdot 4$, but the small number of admissions produced wide confidence intervals. Ten of the admissions with diabetes $(43 \%)$ had pathological disorders that are associated with an increased risk of hypothermia.

The frequency of these conditions is higher in patients with diabetes than in the general population and partly explains the increased risk of hypothermia in these patients.
\end{abstract}

\section{Introduction}

Hypothermia is a recognised complication of diabetic ketoacidosis ${ }^{12}$ and hypoglycaemia,${ }^{3}{ }^{4}$ and it may be more common in patients with diabetes than in the general population. The evidence is conflicting: in surveys of admissions to hospital in North America the proportion of diabetic patients varied from $3 \%$ to $54 \% .^{5-8}$ In England Gale and Tattersall found that $21 \%$ of patients admitted with hypothermia in Nottingham suffered from diabetes. ${ }^{2}$ Their impression was that in the absence of diabetic metabolic emergency conditions hypothermia was no more common in patients with stable diabetes than in the general population. To investigate this we studied the incidence of admissions to hospital with hypothermia in an elderly population.

\begin{abstract}
Methods
Patients aged 65 or over with hypothermia were identified prospectively on admission to three accident and emergency departments in neighbouring health districts in the Oxford region. Rectal temperatures were measured with a low reading mercury thermometer in patients with suspected hypothermia and in patients with an oral temperature of less than $35.5^{\circ} \mathrm{C}$. Hypothermia was defined as a rectal temperature of less than $35^{\circ} \mathrm{C}$. Admissions were recorded from the beginning of November to the end of March for three years. The case notes of patients admitted were examined to obtain a clinical summary, to identify patients with diabetes diagnosed before their admission with hypothermia, and to exclude patients who lived
\end{abstract}

Department of Community Medicine and General Practice, University of Oxford

H A W NEIL, MSC, MRCP, clinical lecturer

I E BAKER, MB, BS, Nuffield Dominions fellow

District Department of Community Medicine, Oxfordshire Health Authority J A DAWSON, MFCM, senior registrar

Correspondence to: Dr H A W Neil, Department of Medicine, Floor 4, Clinical Block, The Medical School, Newcastle upon Tyne NE2 4HH. outside the catchment area of the survey. The Hospital Activity Analysis diagnostic index was searched for patients admitted with a principal or supplementary diagnosis of accidental hypothermia (ICD code $991 \cdot 6$, ninth revision) to identify patients not detected in the survey.

The number of elderly patients with diabetes in the catchment population was estimated from age specific prevalence rates for patients known to have diabetes ascertained in 1982 in a defined area of Oxford with a population of 40079 . These rates were $4 \cdot 70 \%$ for men and $2 \cdot 72 \%$ for women aged $65-74$, and $4 \cdot 12 \%$ for men and $3 \cdot 16 \%$ for women aged 75 or over. The rates of admission of diabetic and non-diabetic patients with hypothermia were calculated per 1000 person years at risk. ${ }^{9}$ Rates were calculated separately for each sex because the prevalence of known diabetes differs for men and women. They were then recalculated after excluding diabetic metabolic emergency cases. The ratios of admission rates and $95 \%$ confidence intervals ${ }^{10}$ are reported.

\section{Results}

\section{PATIENTS ADMITTED WITH HYPOTHERMIA}

A total of 134 cases of accidental hypothermia (table I) occurring in 130 patients were admitted; 23 admissions (17\%) occurred in 20 diabetics. Women made up $87 \%$ of the diabetic and $76 \%$ of the non-diabetic admissions. Only five of the diabetic admissions were treated with insulin, 11 were receiving sulphonylureas, four were being treated by diet alone, and three were not receiving treatment. On admission the rectal temperature of 15 of the diabetic admissions was $33^{\circ} \mathrm{C}$ or less; the lowest recorded temperature was $26^{\circ} \mathrm{C}$.

\section{CLINICAL FEATURES}

A precipitating cause of hypothermia was diagnosed in 15 admissions for hypothermia $(65 \%)$. Diabetic metabolic emergency cases accounted for a third of these: there was one case of non-ketotic hyperosmolar coma, two of ketoacidosis, and two of biochemically proved hypoglycaemia. There were three cases of hypothermia occurring secondary to a fall, two cases of cerebrovascular accident, and a further five cases of respiratory or urinary tract infection.

In the remaining eight admissions (occurring in seven patients), though there was no clear precipitating cause of hypothermia, there were several pathological conditions that are associated with both diabetes and hypothermia. Three patients were receiving treatment for hypothyroidism, one patient with Addison's disease was admitted twice, two patients had autonomic neuropathy, and one patient had congestive heart failure. In three cases pre-existing congestive cardiac failure complicated the primary disease. Two admissions were taking benzodiazepines, but no other cases were taking drugs known to impair thermoregulation.

\section{ADMISSION RATES}

The catchment population aged 65 or over was almost $157000(59 \%$ women) and, during the winters of $1981-2$ to $1983-4$, provided nearly 196200 person years of exposure over the 15 months surveyed. The admission rate for hypothermia in women was substantially higher in diabetic than in non-diabetic patients (table II) and was highest in those aged 65-74, with a ratio of diabetic to non-diabetic admission rates of $35 \cdot 8$. For those aged 75 or over, though the ratio of 5.5 was lower, the difference in admission rates was greater. Excluding diabetic metabolic emergency cases made little difference (table II).

In men aged 65-74 the admission rate was no higher in diabetic than in non-diabetic patients (the estimate of the ratio of admission rates is not informative because there were no diabetic cases: confidence intervals are therefore not reported). In those aged 75 or over the ratio of diabetic to nondiabetic admission rates was only just significantly higher (table II) but not after diabetic metabolic emergency cases had been excluded. The combined ratio for men and women was $5 \cdot 7(95 \%$ confidence interval $3 \cdot 8$ to $8 \cdot 3)$. 


\section{Discussion}

In our survey $23(17 \%)$ of the elderly admissions with hypothermia had diabetes that had been previously diagnosed. This conflicts with some North American case series that have reported a much smaller proportion of diabetic patients among admissions of all ages. ${ }^{6}{ }^{8}$ They also described a history of acute alcohol ingestion in over $60 \%$ and exposure in over half of the cases admitted, which suggests that the cases were unrepresentative of the general population.

In England the study in Nottingham by Gale and Tattersall was carefully designed but identified only admissions for more severe hypothermia with a rectal temperature of $33^{\circ} \mathrm{C}$ or less..$^{2}$ It included patients of all ages and identified them retrospectively by reviewing metabolic emergency admissions are excluded. This is unlikely to be explained simply by more intensive medical surveillance of female diabetic patients than non-diabetics resulting in a higher rate of hospital referrals. Many conditions predisposing non-diabetic patients to hypothermia also require continuous medical supervision. "The higher incidence of hypothermia in elderly women with diabetes is partly explained by an association of hypothermia with several pathological conditions that are more common in diabetic patients, particularly women.

The Framingham study found that the risk of congestive heart failure was $2 \cdot 4$ times higher in diabetic men and 5.3 times higher in diabetic women than in non-diabetics. ${ }^{12}$ In a recent Finnish study the cerebrovascular mortality risk ratio among diabetics newly diagnosed at the time of the survey was 5.8 for men and 8.9 for

\begin{tabular}{|c|c|c|c|c|c|c|c|c|c|}
\hline \multicolumn{5}{|c|}{ Non-diabetics } & \multicolumn{5}{|c|}{ Diabetics } \\
\hline \multirow{2}{*}{$\begin{array}{c}\text { Age } \\
\text { (years) }\end{array}$} & \multicolumn{2}{|c|}{ Men } & \multicolumn{2}{|c|}{ Women } & \multicolumn{2}{|c|}{ Men } & \multicolumn{2}{|c|}{ W'omen } & \multirow{2}{*}{$\begin{array}{c}\text { Total } \\
\text { admission }\end{array}$} \\
\hline & $\overline{\text { Population }^{\star}}$ & Cases & Population ${ }^{\star}$ & Cases & Population ${ }^{\star}$ & Cases & Population ${ }^{\star}$ & Cases & \\
\hline $65-74$ & 41000 & 5 & 51000 & 6 & 2022 & 0 & $1+25$ & 6 & 17 \\
\hline $75+$ & 20100 & 22 & 39300 & 78 & 863 & 3 & 1284 & 14 & 117 \\
\hline Total & 61100 & 27 & 90300 & 84 & 2885 & 3 & 2709 & 20 & 134 \\
\hline
\end{tabular}

${ }^{\star}$ Estimates for midpoint of survey.

TABLE II-Rates of admission ${ }^{\star}$ for hypothermia and ratio of diabetic to non-diabetic rates (figures in parentheses are rates after diabetic metabolic emergencies have been excluded )

\begin{tabular}{|c|c|c|c|c|c|}
\hline \multirow{2}{*}{$\begin{array}{c}\text { Age } \\
\text { (years) }\end{array}$} & \multicolumn{2}{|c|}{ Rates of admission $\star$} & \multirow[b]{2}{*}{ Ratio } & & \\
\hline & Non-diabetics & Diabetics & & \multicolumn{2}{|c|}{$95 \%$ Confidence intervals } \\
\hline \multicolumn{6}{|c|}{ Men } \\
\hline $\begin{array}{l}65-74 \\
75+\end{array}$ & $\begin{array}{l}0.10 \\
0.88\end{array}$ & $\begin{array}{l}0 \\
2 \cdot 78(1.85)\end{array}$ & $3 \cdot 17(2 \cdot 10)$ & 1.01 to 9.94 & $(0.51$ to 8.71$)$ \\
\hline Total & $0 \cdot 35$ & $0.83(0.55)$ & $2.35 \quad(1.57)$ & 0.74 to 7.48 & $(0.38$ to 6.51$)$ \\
\hline \multicolumn{6}{|c|}{ W'omen } \\
\hline $65-74$ & 0.09 & $3 \cdot 37(2 \cdot 25)$ & $35 \cdot 77(23 \cdot 85)$ & $17 \cdot 83$ to $71 \cdot 76$ & $(10.11$ to $56 \cdot 22)$ \\
\hline $75+$ & 1.59 & $8 \cdot 72(7 \cdot 48)$ & $5 \cdot 50 \quad(4 \cdot 71)$ & $3 \cdot 32$ to $9 \cdot 12$ & $(2 \cdot 72$ to 8.18$)$ \\
\hline Total & 0.74 & $5.91(4.72)$ & $7.94 \quad(6.35)$ & $5 \cdot 27$ to $11 \cdot 96$ & $(3.99$ to 10.11$)$ \\
\hline
\end{tabular}

^Per 1000 person years for November to March inclusive.

separate listings for diabetes and hypothermia in the Hospital Activity Analysis over seven years. In our prospective survey only $15(65 \%)$ of our diabetic admissions with hypothermia had a rectal temperature of $33^{\circ} \mathrm{C}$ or less, and only four admissions $(17 \%)$ appeared in the records of the Hospital Activity Analysis with a diagnosis of both diabetes and hypothermia. Despite differences in study design the proportion of diabetic admissions in the Nottingham survey closely resembled our findings. This suggests that the proportion of diabetic patients is similar among patients admitted with hypothermia of different degrees of severity. Direct comparison between surveys of hospital incidence rates is not possible because rates have not been reported previously.

Most surveys have shown that most admissions to hospital for hypothermia occur during winter in the elderly. Maclean and Emslie-Smith reported that 85 of 100 consecutive cases of hypothermia occurred in patients over the age of 60 , and most of these had an identifiable illness that predisposed them to hypothermia." We found a clear precipitating cause of hypothermia in about $65 \%$ of diabetic cases admitted. In the remaining cases, though no clear cause was identified, each patient had one or more underlying condition known to be associated with hypothermia.

Hospital incidence inevitably underestimates the true incidence of hypothermia. We have shown, however, that there is a much higher hospital incidence of hypothermia in elderly women with diabetes than in the general population, even after diabetic women. ${ }^{13}$ Endocrinopathies are also more common in patients with diabetes; one study reported a $1 \cdot 7 \%$ prevalence of primary hypothyroidism in diabetics, ${ }^{14}$ and another found that $80 \%$ of these patients were women. ${ }^{15}$ Autonomic neuropathy and diminished thermal discrimination also impair thermoregulation and are common in diabetics, though the precise incidence and possible differences between men and women remain unknown. ${ }^{16}{ }^{17}$ Malnutrition impairs thermoregulation too, ${ }^{18}$ but there is no evidence that it is more common in diabetic patients, particularly elderly women, than in the general population.

In contrast with our results for women our results showed little difference between the incidence of hypothermia in elderly diabetic and non-diabetic men. This needs to be confirmed because the difference between the ratios of admission rates for men and women was not significant, and the upper confidence interval of $7 \cdot 5$ for men overlapped the lower confidence interval for women. A difference between the sexes could be explained partly by the higher prevalence in women of disorders that predispose them to hypothermia and by differences in the pattern of mortality. The poorer survival of men may be associated with physiological factors related to susceptibility to hypothermia. Fewer men survive to old age, and they may be less susceptible to hypothermia than elderly women.

We conclude that hypothermia is more common in elderly women with diabetes than in the general population, even after diabetic metabolic emergency cases are excluded. Diabetes is an 
important factor to consider when assessing the risk of hypothermia in elderly women, particularly if they are exposed to low environmental temperatures in the home.

We thank Dr Klim McPherson for statistical advice.

\section{References}

1 Alberti KGMM, Hockaday TDR. Diabetic coma: a reappraisal after five years. Clin Endocrinol Metab 1977;6:431.

2 Gale EAM, Tattersall RB. Hypothermia: a complication of diabetic ketoacidosis. Br Med $\mathcal{J}$ 1978;iv: $1387-9$.

3 Strauch BS, Felig P, Baxter JD, Schimpff SC. Hypothermia in hypoglycemia. JAMA 1969;210:345-6.

4 Molnar GW, Read RC. Hypoglycemia and body temperature. JAMA 1974;227:916-21

5 Davidson M, Grant E. Accidental hypothermia. Postgrad Med 1961;5:42-9.

6 O'Keefe KM. Accidental hypothermia: a review of 62 cases. Journal of the American College of Emergency Physicians 1977;6:491-6.

7 Tolman K, Cohen A. Accidental hypothermia. Can Med Assoc 3 1970;103:1357-61

8 White JD. Hypothermia: the Bellvue experience. Ann Emerg Med 1982;11:417-24
9 Oleinich A, Mantel N. Family studies in systemic lupus erythematosus. II. Mortality amongst siblings and offspring of index cases with a statistical appendix concerning life table analysis. f Chronic Dis 1970;22:617-25.

10 Miettenen O. Estimability and estimation in case referrent studies. Am $\mathcal{F}$ Epidemiol 1976;103: 226-35.

11 Maclean D, Emslie-Smith D. Accidental hypothermia. Oxford: Blackwell Scientific Publications, 1977:284-5.

12 Kannel WB, Hjortland $M$, Castelli WP. Role of diabetes in congestive heart failure: the Framingham study. Am $\mathcal{J}$ Cardiol 1974;34:29-34.

13 Pylorala K, Laakso M. Macrovascular disease in diabetes mellitus. In: Mann JI, Pylorala K, Teuscher A, eds. Diabetes in epidemiological perspective. Edinburgh: Churchill Livingstone, 1983:222.

14 Hecht A, Gershberg H. Diabetes mellitus and primary hypothyroidism. Metabolism 1968;17: $108-13$.

15 Ganz K, Kozak GP. Diabetes mellitus and primary hypothyroidism. Arch Intern Med 1974;134: 430-2.

16 Exton-Smith AN. The elderly in a cold environment. In: Arie T, ed. Health care of the elderly. London: Croom Helm, 1981:42-56.

17 Collins KJ, Exton-Smith AN, Dore C. Urban hypothermia: preferred temperature and thermal perception in old age. BrMed f 1981;282:175-7.

18 Fellows IW, Macdonald IA, Bennett T, Allison SP. The effect of undernutrition on thermoregulation in the elderly. Clin Sci 1985;69:525-32.

(Accepted 13 fune 1986)

\title{
Effects of living with and looking after survivors of a stroke
}

\author{
DERICK T WADE, JULIA LEGH-SMITH, RICHARD LANGTON HEWER
}

\begin{abstract}
Information from a two year, longitudinal study on a community sample of patients with acute stroke was analysed to determine the effects of the stroke on the mood of the chief carer (the person living with the patient). Increased anxiety was the most commonly reported change six months after stroke. Significant depression was seen in $11-13 \%$ of carers over the first two years after stroke. The patient's functional disability was associated with depression in the carer over the first year but not at two years. A perceived poor recovery by the patient, a low level of general activities by the patient, and depression in the patient were also associated with depression in the carer within the first year. At two years after stroke none of the measured factors were related to a carer's level of depression.

Carers of patients who have suffered stroke showed anxiety and emotional distress unrelated to the patient's physical disability after two years. More help from stroke support groups for carers is perhaps needed.
\end{abstract}

\section{Introduction}

"Stroke is a family matter." Many survivors, left disabled after stroke, remain at home for months or years, cared for by their family. Caring is a labour of love intimately related to the woman's role, ${ }^{2}$ though it is also recognised as a service warranting encouragement. ${ }^{3}$ But at what cost to that family? About half of these families may suffer financial stress, perhaps because someone has to stop work,,$^{14}$ and loss of social life may affect three quarters of carers. ${ }^{1}$ Medical and psychiatric disturbance may be found in up to $60 \%$ of carers, ${ }^{4.6}$ and disruption of sleep, the least tolerated aspect of caring for someone, ${ }^{7}$ is also often a problem. ${ }^{4}$

Most of the studies mentioned above were based on patients

Department of Neurology, Frenchay Hospital, Bristol BS16 1LE

DERICK T WADE, MRCP, neurology research registrar

JULIA LEGH-SMITH, BA, research phychologist

RICHARD LANGTON HEWER, FRCP, consultant neurologist

Correspondence to: $\mathrm{Dr}$ Wade. selected by age, ${ }^{6}$ the presence of aphasia, ${ }^{5}$ or referral for rehabilitation. ${ }^{14}$ This report is based on a community sample that incorporated routine standardised assessments of carers. Its main emphasis is on the prevalence of emotional stress and its associated factors.

\section{Subjects and methods}

In this study the main carer was defined as the person who lived in the same house as the patient and who was most closely associated with the patient. They were not necessarily giving obvious, active support to the patient; they may have been companions rather than carers. Neither wardens nor landladies were included, nor were people living nearby, even if they gave much help. The patients were the survivors from a longitudinal study on all acute strokes (defined clinically ${ }^{8}$ ) arising in a specified health district population of 215000 people. ${ }^{9}$ Each patient and carer was assessed at three weeks, six months, one year, and two years.

Psychiatric morbidity in carers was assessed using the Wakefield self assessment depression inventory ${ }^{10}$ - the 28 question version of the general health questionnaire 11 -and by asking them directly about various mood changes in relation to their state before the stroke (see table II). The Wakefield inventory has 12 questions giving a score between 0 and 36 . As with the patients, ${ }^{12}$ a score on the Wakefield inventory of $15-18$ has been classified as probable depression, with higher scores being classified as definite depression (the mood, not necessarily the clinical illness). Each patient and his or her carer were also asked independently to rate the patient's recovery of independence on a line scale $150 \mathrm{~mm}$ long, the end points being "the worst he was after the stroke" and "as he was before the stroke." Aspects of each patient's state were assessed using the Barthel index of activities of daily living, ${ }^{13}$ the Wakefield inventory, the Frenchay activities index,$^{14}$ and the Hodkinson mental scale for confusion. ${ }^{15}$

\section{Results}

One year after their stroke 372 patients were at home but 70 lived alone, leaving $302(81 \%)$ with a carer; 81 had more than one person in the house. The main carer was a spouse for $257(85 \%)(86(28 \%)$ were husbands), a son or daughter for $25(8 \%)$, a brother or sister for $13(4 \%)$, and a more distant relative or friend for $7(2 \%)$. The effect of the stroke on a carer's work was recorded six months after the stroke, when 393 surviving patients were at home with a carer. Ninety four carers $(24 \%)$ had worked before the stroke: $72(77 \%)$ of these were working at six months, $15(16 \%)$ had stopped, $4(4 \%)$ had increased their work, and $2(2 \%)$ had reduced their work. One person had started work. One hundred carers $(33 \%)$ could drive. 